\title{
Structure-activity relationship analysis of cytotoxic cyanoguanidines: selection of CHS 828 as candidate drug Henrik Lövborg1, Robert Burman ${ }^{2}$ and Joachim Gullbo*3
}

Address: ${ }^{1}$ Division of Clinical Pharmacology, Faculty of Health Sciences, Department of Medicine and Care, Linköping University, SE-581 85 Linköping, Sweden, ${ }^{2}$ Division of Pharmacognosy, Department of Medicinal Chemistry, Uppsala University, Biomedical Centre, Box 574 , SE-751 23 Uppsala, Sweden and ${ }^{3}$ Division of Clinical Pharmacology, Uppsala University Hospital, SE-751 85 Uppsala, Sweden

Email: Henrik Lövborg - henrik.lovborg@lio.se; Robert Burman - robert.burman@fkog.uu.se; Joachim Gullbo* - joachim.gullbo@medsci.uu.se * Corresponding author

Published: 29 June 2009

BMC Research Notes 2009, 2:114 doi:10.1186/1756-0500-2-II4
Received: 3 October 2008

Accepted: 29 June 2009

This article is available from: http://www.biomedcentral.com/I756-0500/2/II4

(C) 2009 Gullbo et al; licensee BioMed Central Ltd.

This is an Open Access article distributed under the terms of the Creative Commons Attribution License (http://creativecommons.org/licenses/by/2.0), which permits unrestricted use, distribution, and reproduction in any medium, provided the original work is properly cited.

\begin{abstract}
Background: N-(6-(4-chlorophenoxy)hexyl)-N'-cyano-N"-4-pyridyl guanidine) (CHS 828) is the first candidate drug from a novel group of anti-tumour agents - the pyridyl cyanoguanidines, shown to be potent compounds interfering with cellular metabolism (inhibition of nicotinamide phosphoribosyl transferase) and NF- $\kappa B$ signalling. Substituted cyanoguanidines are also found in anti-hypertensive agents such as the potassium channel opener pinacidil ( $N$-cyano- $N$ '-(4-pyridyl)$N "-(I, 2,2$-trimethylpropyl)guanidine) and histamine-II receptor antagonists (e.g. cimetidine, $N$ cyano-N'-methyl-N"-[2-[[(5-methylimidazol-4-yl]methyl]thio]ethyl)guanidine). In animal studies, CHS 828 has shown very promising activity, and phase I and II studies resulted in further development of a with a water soluble prodrug.
\end{abstract}

Findings: To study the structural requirements for cyanoguanidine cytotoxicity a set of 19 analogues were synthesized. The cytotoxic effects were then studied in ten cell lines selected for different origins and mechanisms of resistance, using the fluorometric microculture cytotoxicity assay (FMCA). The compounds showed varying cytotoxic activity even though the dose-response curves for some analogues were very shallow. Pinacidil and cimetidine were found to be non-toxic in all ten cell lines. Starting with cyanoguanidine as the crucial core it was shown that 4-pyridyl substitution was more efficient than was 3-pyridyl substitution. The 4-pyridyl cyanoguanidine moiety should be linked by an alkyl chain, optimally a hexyl, heptyl or octyl chain, to a bulky end group. The exact composition of this end group did not seem to be of crucial importance; when the end group was a mono-substituted phenyl ring it was shown that the preferred position was 4substitution, followed by 3- and, finally, 2-substitution as the least active. Whether the substituent was a chloro, nitro or methoxy substituent seemed to be of minor importance. Finally, the activity patterns in the ten cell lines were compared. Substances with similar structures correlated well, whilst substances with large differences in molecular structure demonstrated lower correlation coefficients.

Conclusion: According to this structure-activity relationship (SAR) study, CHS 828 meets the requirements for optimal cytotoxic activity for this class of compounds. 


\section{Background}

The anti-tumoral activity of the pyridyl cyanoguanidines was first detected in a routine in vivo screening programme in a rat model with Yoshida ascites sarcoma cell tumours. The studied compounds were synthesized as analogues to the anti-hypertensive potassium channel opener pinacidil (Fig. 1). Replacement of the side chain by longer aryl-containing side chains caused a loss of activity in this respect, and a candidate drug, $\mathrm{N}$-(6-(4-chlorophenoxy)hexyl)- $\mathrm{N}^{-}$cyano- $N "-4$-pyridyl guanidine) (CHS 828), was selected after studies of structure-activity relationships (SARs) in vitro and preliminary evaluation in vivo [1].

Cyanoguanidines hyperpolarizing adenosine triphosphate (ATP)-sensitive potassium channels in the smooth muscle of the bladder have received attention as drug candidates for overactive bladder. One example is shown in Figure 1[2]. In addition to their appearance in pinacidil and other potassium channel openers (on which CHS 828 has no activity), substituted cyanoguanidines are also found in histamine-II receptor antagonists (e.g. cimetidine, N-cyano-N'-methyl-N"-[2-[[(5-methylimidazol-4yl]methyl]thio]ethyl)guanidine) (Fig. 1).

As CHS 828 displays a broad spectrum of activity, low cross-resistance with standard drugs, favourable in vitro therapeutic indices $[1,3,4]$ and $\mathrm{IC}_{50}$ values in the nanomolar range, the drug was brought into phase I clinical trials $[5,6]$. A detailed description of the mechanism of action of CHS 828 was not presented until 2004 when Dr Stangelshøj Olsen and co-workers published data sup- porting inhibition of the Inhibitory $\kappa$-B kinase (IKK) complex, with an $\mathrm{IC}_{50}$ of $8 \mathrm{nM}$ [7]. The mechanism of action may, however, be dual, and may in part depend on drug concentration and exposure time as suggested by Hassan et al [8]. According to Ekelund et al [9], high concentrations ( 1 and $10 \mu \mathrm{M}$, well exceeding the $\mathrm{IC}_{50}$ ) of CHS 828, just like meta-iodobenzyl guanidine (MIBG), inhibit mitochondrial respiration, with a subsequent increase in glycolysis to cover the energy need. Interestingly, this high concentration effect is similar in resistant U-937/CHS cells and the U-937 GTB cells [9]. In addition, it was shown that cells grown in pyruvate-supplemented, glucose-free medium are, at least partly, protected from CHS 828 toxicity, thereby indicating that the extent of glycolysis may be an important determinant of optimal CHS 828 activity [9]. The process following CHS 828 exposure is characterized by an almost normal proliferation during the first 24 hours followed by an abrupt shut-off of deoxyribonucleic acid (DNA) and protein synthesis, a modest increase in caspase-3 activity and DNA fragmentation, and the first signs of cell death $[10,11]$. These processes seem dependent on intact protein synthesis [10]. Addition of the adenosine diphosphate (ADP) ribosylation inhibitor 3-aminobenzamide to the medium and U-937 cells exposed to CHS 828 resulted in a 100-fold decrease in $\mathrm{IC}_{50}$, and also in more predominant apoptotic cell death [12]. This effect, however, appears to be unrelated to the effects on poly(ADP-ribose) polymerase (PARP), and the authors suggest that it is mediated through effects on glycolytic enzymes, such as glyceraldehyde-3-phosphate [12]. In the subsequent paper it was shown that
A<smiles>N#C/N=C(\NCCCCCCOc1ccc(Cl)cc1)Nc1ccncc1</smiles><smiles>CC(N/C(=N\C#N)Nc1ccncc1)C(C)(C)C</smiles>

B2<smiles>CC(C)(C)C(NC(=O)c1ccc(Cl)cc1)N/C(=N\C#N)Nc1cccnc1</smiles>

Figure I

Substituted cyanoguanidines with defined pharmacological effects: A Cytotoxic CHS 828; B Potassium channel openers pinacidil (B I) and I $2 \mathrm{~g}$ of compound as described in Perez-Medrano et al [2] (B2); and C Histamine-II receptor antagonist cimetidine. 
PARP-1 inactivation in mouse fibroblasts in fact sensitizes cells to the cytotoxic action of CHS 828, and consequently, that the drug is able to activate different cellular pathways depending on PARP status [13]. During the 2007 American Association for Cancer Research/National Cancer Institute/European Organization for Research and Treatment of Cancer (AACR-NCI-EORTC) International Conference on Molecular Targets and Cancer Therapeutics, Roulston and co-workers at Gemin X Biotechnologies Inc. presented data strongly suggesting that GMX1778 (EB1627), a soluble prodrug of CHS 828, acts by inhibition of nicotinamide phosphoribosyl transferase (Nampt), an enzyme involved in nicotinamide adenine dinucleotide (oxidized) (NAD+) biosynthesis, and that nuclear factor-kappa $\mathrm{B}(\mathrm{NF}-\kappa \mathrm{B})$ inhibition is only a consequence of $\mathrm{NAD}+$ decline [14]. This mechanism was recently confirmed in a study by Dr Høgh Olesen and coworkers, including cross-resistance to FK866, a known inhibitor of Nampt [15]. Nampt has also been presumed to be a cytokine (PBEF) or a hormone (visfatin). The crystal structure of Nampt in the presence and absence of nicotineamide mononucleotide shows that Nampt is a dimeric type II phosphoribosyltransferase and provides insights into the enzymatic mechanism [16]. Previously noted effects by CHS 828 on glycolysis and inhibition of the transcription factor NF- $\kappa \mathrm{B}$ can likely be secondary to inhibition of Nampt.

The aim of this study was to establish the structural requirements for cyanoguanidine cytotoxicity. The cytotoxic effects of nineteen substituted pyridyl cyanoguanidines, with variations in pyridyl substitution, different alkyl chain linkers and end groups, were studied on a panel of ten cell lines.

\section{Methods \\ Cell lines}

Cytotoxicity was assayed in a panel of ten human tumour cell lines. This panel was previously established for use in the early investigation of new anti-cancer compounds, and the cell lines represent different histological origins and mechanisms of resistance [17]. The panel has successfully been used in in vitro evaluation of a wide range of different cytotoxic agents, both for clinical and for investigational purposes. A brief description of the cell lines is presented in Table 1. Cells were maintained as previously described [17].

\section{Medium and reagents}

Cell growth medium RPMI-1640 (Sigma Chemical Co., St. Louis, MO, USA) supplemented with $10 \%$ heat-inactivated foetal calf serum (FCS) (Sigma), $2 \mathrm{mM}$ glutamine, $100 \mu \mathrm{g} / \mathrm{mL}$ streptomycin and $100 \mathrm{U} / \mathrm{mL}$ penicillin was used for all experiments. Fluorescein diacetate (FDA) (Sigma) was dissolved in dimethylsulphoxide (DMSO) (Sigma) to a concentration of $10 \mathrm{mg} / \mathrm{mL}$ and kept frozen as a stock solution in the dark.

\section{Test compounds}

The test compounds, a set of 19 structure analogues to CHS 828 with the cyanoguanidine core preserved, was a kind gift from the Department of Chemical Research, Leo Pharma, Ballerup, Denmark. Compounds were synthesized using methods described elsewhere $[1,9]$.

\section{Cytotoxicity assay}

The FMCA has been previously described in detail [1820]. The method is based on 72-hour drug exposure in 96well microtitre plates, whereafter cells are washed and the fluorescence generated from hydrolysis of fluorescein diacetate is measured. Fluorescence is proportional to the number of living cells in the well. The method has been used extensively for experimental as well as clinical purposes, and seems valuable with most classes of chemotherapeutic drugs. For concentration-response curves, each drug was tested at five different concentrations, each concentration in triplicate. Each 96-well microtitre plate had six control (unexposed cells) and six blank (cell medium only) wells. Quality criteria for a successful assay included $>90 \%$ starting viability (judged by Trypan blue exclusion), a control signal more than ten times the blank, and, finally, a coefficient of variation in control and blank wells of $<30 \%$.

\section{Statistical analysis}

Direct comparisons of the activity for the substances were made by using paired $t$-tests in GraphPad Prism, version 4 (Graphpad Software Inc., La Jolla, CA, USA).

Table I: Cell line characteristics

\begin{tabular}{lllll}
\hline Parental cell line & Sub-line(s) & Origin & Selecting agent & Proposed resistance mechanism \\
\hline CCRF-CEM & CEM/NM-I & Leukaemia & Teniposide & Topo II-associated \\
NCI-H69 & H69/AR & SCLC & Doxorubicin & MRP \\
RPMI8226/S & $8226 /$ Dox40 & Myeloma & Doxorubicin & PgP \\
& $8226 /$ LR5 & & Melphalan & GSH \\
U-937 GTB & U-937 Vcr & Lymphoma & Vincristin & Tubulin-associated \\
ACHN & - & Renal & & Primary resistant
\end{tabular}

GSH = glutathione; PgP = p-glycoprotein I70; SCLC = small-cell lung cancer; Topo II = topo-isomerase II MRP = Multidrug resistance associated protein 


\section{Results}

The compounds showed varying cytotoxic activity allowing the SAR analysis; however, the dose-response curves for some analogues were very shallow, in several cases ending in a plateau at a survival index of $20-80 \%$, thereby preventing a correct determination of the $\mathrm{IC}_{50}$ value. This characteristic dose-response profile has been previously described for CHS 828 in the fluorometric microculture cytotoxicity assay (FMCA) [3]. Prolonged assay time (violation to standard FMCA protocol) to 144 hours produced better dose-response curves and allowed determination of the $\mathrm{IC}_{50}$ values, results were similar but slightly changed (not shown). To avoid interference the survival index at $10 \mu \mathrm{M}$ (on the plateau) was used with FMCA assay time 72 hrs (standard protocol). In a phase I trial reported by Ravaud et al [5] CHS 828 was given orally as a singe dose every 3 weeks. Doses up to $500 \mathrm{mg}$ was given, which resulted in plasma concentrations of $11 \mu \mathrm{M}$. The inherent order of sensitivity among the cell lines was similar to that presented previously [3], with the doxorubicin resistant small-cell lung cancer (SCLC) cell line H69AR being the most sensitive and the maternal myeloma cell line RPMI 8226 S being highly sensitive, while the doxorubicinselected (p-glycoprotein (Pgp)-expressing) sub-line, 8226 Dox40, displayed a considerable degree of resistance, as did the T-cell leukaemia lines CCRF-CEM and CEM/R. This pattern of activity among the cell lines was similar for most of the compounds (see below). The reference compounds pinacidil and cimetidine (Fig. 1) were tested in concentrations of up to $10 \mathrm{mM}$ in all ten cell lines and were found to be non-toxic (not shown).

First, the pyridyl substitution pattern on the cyanoguanidine core was studied. As seen in Figure 2, 4-pyridyl substitution was significantly more efficient than was 3pyridyl substitution $(\mathrm{p}<0.01)$.

Second, the linking alkyl chain length was examined. This factor was apparently of considerable importance, having optimum activity with hexyl, heptyl or octyl chains ending with a bulky end group (Fig. 3). The exact composition of this end group did not seem to be of crucial importance (Fig. 4A). When the end group was a monosubstituted phenyl ring it was shown that the preferred position was 3-substitution, followed by 2- and, finally, 4substitution, but differences were minor. The compound with an unsubstituted phenyl was as active as the 4-substituted compounds, while the trichlorinated derivative appeared less active (however, the difference was statistically not significant; $\mathrm{p}=0.13$ ). Whether the substituent(s) was a chloro- or methoxy-group(s) seemed to be of minor importance (Fig. 4B).

Finally, the activity patterns in the ten cell lines were compared. Substances with similar structures correlated well, whilst substances with large differences in molecular

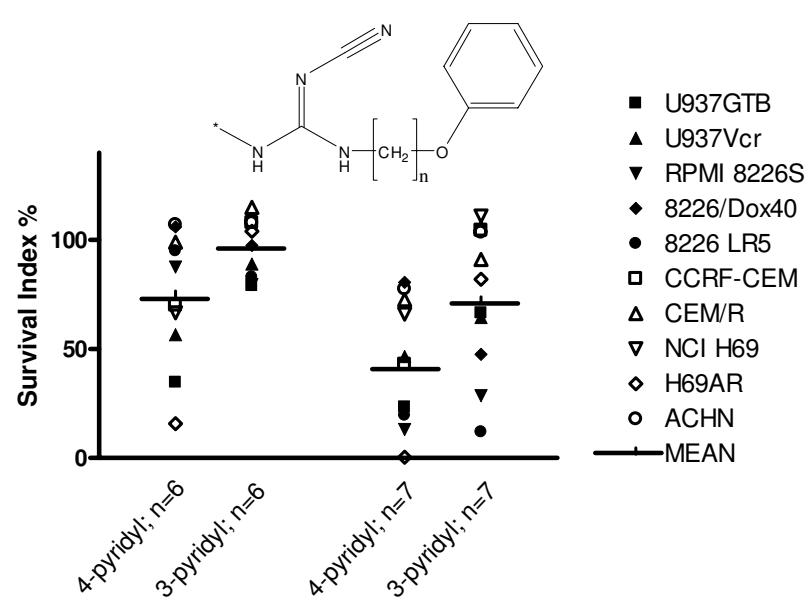

Figure 2

Effects of pyridyl substitution pattern on cytotoxic activity (as survival index at $10 \mathrm{M}$ ) in the ten cell lines studied. The symbols for each cell line is used in figure $2-4$.

structure demonstrated lower correlation coefficients (not shown).

\section{Discussion}

The unsubstituted pyridyl moiety appears important, although it has not been studied in detail in the present study. Others have shown that a substituted pyridyl or a phe-

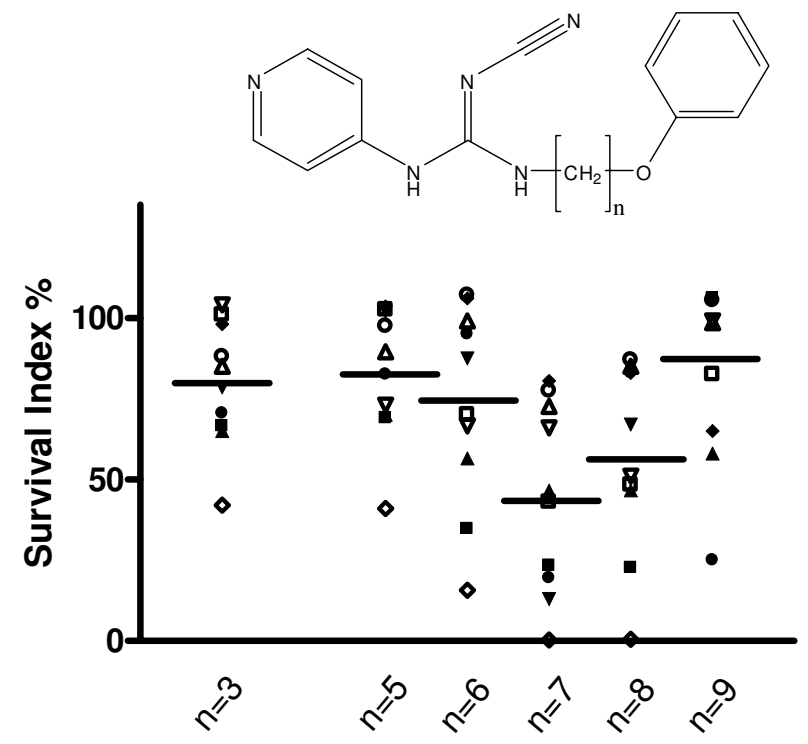

Figure 3

Effects of linking chain length on cytotoxic activity (as survival index at $10 \mathrm{M}$ ) in the cell lines studied. Symbols as in figure 2 . 

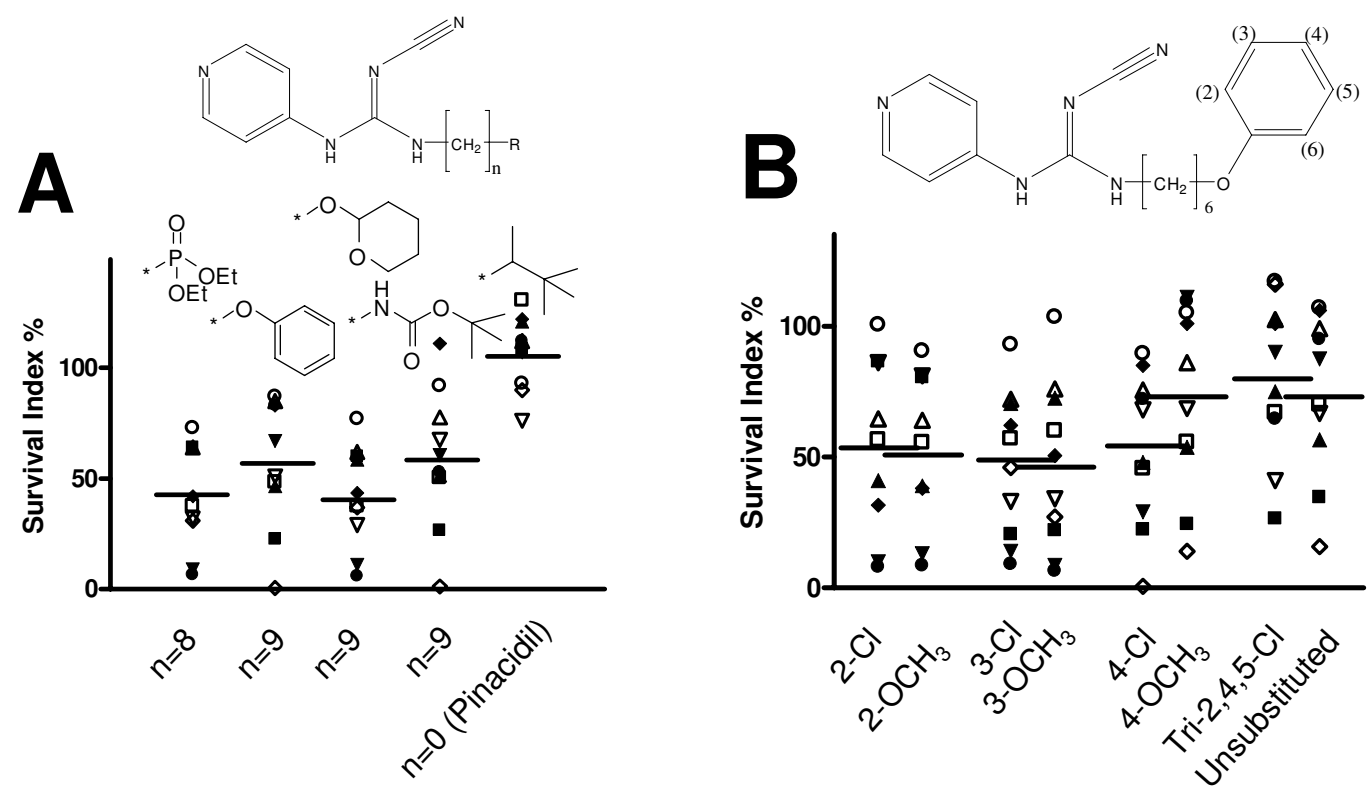

\section{Figure 4}

Effects of different end groups (4A); and end group substituents (4B), on cytotoxic activity (as survival index at $10 \mathrm{M}$ ) in the cell lines studied. Symbols as in figure 2.

nyl substituent strongly reduces the cytotoxic activity of the compounds. Interestingly, however, N-(6-(4-chlorophenoxy)hexyl)-N'-cyano-N"-((2-methoxy)-5-pyridyl guanidine is a fairly potent inhibitor of the IKK activity in vitro $\left(\mathrm{IC}_{50} 22 \mathrm{nM}\right.$ v. $8.0 \mathrm{nM}$ for CHS 828), which contrasts with its low anti-proliferative activity against NYH SCLC cells in vitro and in vivo [7], and consequently in this particular case the cytotoxic action and the IKK inhibitory action appear separate. Furthermore, while retaining the capacity of increasing the glycolytic activity in U-937 cells, this compound appears to be almost atoxic also in this cell line (compound 8 in Ekelund et al [9]), again leading to speculations about a dual mechanism of action. Compounds with the pyridyl ring substituted for a mono or unsubstituted phenyl ring display no IKK inhibitory or cytotoxic activity [7]. Arylcyanoguanidines with short aliphatic side chains (e.g. $N$-aryl-N'-cyano- $N$ "alkyl-guanidines) are known as activators of ATP-sensitive potassium channels and inhibitors of insulin release from beta cells, but small structural changes can dramatically change the efficacy [21].

The length of the alkyl chain linking the cyanoguanidine to a bulky end group proved to be important, ideally being an hexyl to an octyl chain, in agreement with a previous report from Schou and co-workers [1]. In light of this, it is worth noting that the dodecyl derivative with a tert-butyloxycarbonylamino end group (CHS 850) nevertheless has shown high potency as an inhibitor of IKK activity, as well as proliferation of NYH SCLC cells in vitro and in vivo [7].
It has recently been shown that different $\mathrm{Na}^{+} / \mathrm{H}^{+}$exchange inhibitors, including the cyanoguanidine cimetidine, also inhibit chemokine production and NF- $\kappa \mathrm{B}$ activation in immuno-stimulated endothelial cells [22]. For the model substance in these studies, amiloride (with no structural relationship to the cyanoguanidines), this was suggested to result from an inhibitory effect on $\mathrm{I} \kappa \mathrm{B}$ degradation [22]. Cimetidine and amiloride are both completely nontoxic in the FMCA model in the cell lines studied (Ekelund et al [23] and unpublished data), and interaction analysis between amiloride and CHS 828 in U-937 cells has shown synergistic effects [23].

In order to develop a second-generation drug candidate from CHS 828 with the aim to improve cytotoxicity and/ or selectivity, Chern and co-workers synthesized analogues with a bridge connecting the two amino nitrogens of the cyanoguanidine, thus forming a cyclic structure such as 2-cyanoimino-4-imidazodinone derivatives. Some of these drugs, especially the 5-substituted ones, displayed cytotoxic activities at sub-micromolar level. However, in contrast to the analogue series presented in this paper, the rigid analogues appeared to display a different activity spectrum compared with the model compound (namely, higher activity against colon and liver cancer cell lines, and lower activity against gastric, nasopharyngeal and breast cancer) [24]. However, it is at present unclear whether these compounds with cyclic structures displays a more favourable activity profile than the compounds described in our work. 


\section{Conclusion}

The cytotoxic cyanoguanidines, with CHS 828 as the model compound, have received a fair amount of attention in the scientific literature, and early clinical trials have been performed. Further development resulted in a water soluble prodrug called EB1627 (also denoted GMX1777). Prolonged infusions of EB1627 have recently been reported to yield significant effects in myeloma, small cell lung cancer and colon cancer xenografts, which according to the authors support the design of an open-label, doseescalation trial, in which patients with refractory solid tumors and lymphomas receive $24 \mathrm{~h}$ infusions of EB1627 as a single agent in 3-week cycles. Furthermore, results indicate that nicotinic acid is a potent antidote to treat EB1627 overdose [25].

Despite efforts for 10 years to pinpoint details of the mechanistic events following exposure to the drug, the exact mechanism of action was not established until very recently. Malignant cells display increased demands for energy production and DNA repair, and NAD is required for both processes and is also continuously degraded by cellular enzymes. $\quad N$-(6-(4-chlorophenoxy)hexyl)-N'cyano- $N$ "-4-pyridyl guanidine most probably acts by inhibition of nicotinamide phosphoribosyltransferase (Nampt), a crucial factor in the resynthesis of NAD $[14,15]$. Using a functional non-clonogenic viability assay we identified structural prerequisites for cytotoxicity, and found CHS 828 to be a reasonable drug candidate.

\section{Authors' contributions}

HL and JG contributed equally to the planning, the performance of the experiments and the analysis. $\mathrm{RB}$ was engaged in data analysis and methodology questions, including stability issues and additional laboratory work, upon major revision of the manuscript. The manuscript was mainly written by JG and reviewed by HL and RB.

\section{Declaration of competing interests}

The authors declare that they have no competing interests.

\section{Acknowledgements}

Dr Fredrik Björkling at the Department of Chemical Research, Leo Pharma, Ballerup, Denmark, is gratefully acknowledged for providing test substances.

\section{References}

I. Schou C, Ottosen ER, Petersen HJ, Björkling F, Latini S, Hjarnaa PV, Bramm E, Binderup L: Novel cyanoguanidines with potent oral antitumour activity. Bioorg Med Chem Lett 1997, 7(24):3095-3100.

2. Perez-Medrano A, Buckner SA, Coghlan MJ, Gregg RJ, Gopalakrishnan M, Kort ME, Lynch JK, Scott VE, Sullivan JP, Whiteaker KL, et al.: Design and synthesis of novel cyanoguanidine ATP-sensitive potassium channel openers for the treatment of overactive bladder. Bioorg Med Chem Lett 2004, I 4(2):397-400.

3. Hjarnaa $P$, Jonsson E, Latini S, Dhar S, Larsson R, Bramm E, Skov T, Binderup L: CHS 828, a novel pyridyl cyanoguanidine with potent amtitumour activity in vitro and in vivo. Cancer Res 1999, 59(22):575|-5757.

4. Jonsson E, Friberg LE, Karlsson MO, Hassan SB, Nygren P, Kristensen J, Tholander B, Binderup L, Larsson R: In vivo activity of CHS 828 on hollow-fibre cultures of primary human tumour cells from patients. Cancer Lett 200I, I 62(2): 193-200.

5. Ravaud A, Cerny T, Terret C, Wanders J, Bui BN, Hess D, Droz JP, Fumoleau P, Twelves C: Phase I study and pharmacokinetic of CHS-828, a guanidino-containing compound, administered orally as a single dose every 3 weeks in solid tumours: an ECSG/EORTC study. Eur J Cancer 2005, 4 I (5):702-707.

6. Hovstadius P, Larsson R, Jonsson E, Skov T, Kissmeyer A-M, Krasilnikoff K, Bergh J, Karlsson MO, Lönnebo A, Ahlgren J: A phase I study of CHS 828 in patients with solid tumor malignancy. Clinical Cancer Research 2002, 8(9):2483-2850.

7. Olsen LS, Hjarnaa PJ, Latini S, Holm PK, Larsson R, Bramm E, Binderup L, Madsen MW: Anticancer agent CHS 828 suppresses nuclear factor-kappa $B$ activity in cancer cells through downregulation of IKK activity. Int J Cancer 2004, I I I (2): | 98-205.

8. Hassan SB, Jonsson E, Larsson R, Karlsson MO: Model for time dependency of cytotoxic effect of CHS 828 in vitro suggests two different mechanisms of action. J Pharmacol Exp Ther 200I, 299(3): I|40-। | 47.

9. Ekelund S, Liminga G, Björkling F, Ottosen E, Schou C, Binderup L, Larsson R: Early stimulation of acidification rate by novel cytotoxic pyridyl cyanoguanidines in human tumor cells: Comparison with $\mathbf{m}$-iodobenzylguanidine. Biochem Pharmacol 2000, 60(6):839-849.

10. Martinsson P, Liminga G, Dhar S, de la Torre M, Lukinius A, Jonsson E, Bashir Hassan S, Binderup L, Kristensen J, Larsson R: Temporal effects of the novel antitumour pyridyl cyanoguanidine (CHS 828) on human lymphoma cells. Eur J Cancer 200I, 37:260-267.

II. Martinsson P, de la Torre M, Binderup L, Nygren P, Larsson R: Cell death with atypical features induced by the novel antitumoral drug CHS 828, in human U-937 GTB cells. Eur J Pharmacol 200I, 4I7(3): I8I- I87.

12. Lovborg H, Martinsson P, Gullbo J, Ekelund S, Nygren P, Larsson R: Modulation of pyridyl cyanoguanidine (CHS 828) induced cytotoxicity by 3-aminobenzamide in U-937 GTB cells. Biochem Pharmacol 2002, 63(8): |49|-|498.

13. Lovborg H, Wojciechowski J, Larsson R, Wesierska-Gadek J: Action of a novel anticancer agent, CHS 828, on mouse fibroblasts: increased sensitivity of cells lacking poly (ADP-Ribose) polymerase-I. Cancer Res 2002, 62(I5):4206-42II.

14. Roulston A, Watson M, Bernier C, Chan H, Gratton MO, Jang A, Koch E, Lavoie M, Paquette D, M M: Poster A81; GMXI777: A novel inhibitor of NAD+ biosynthesis via inhibition of nicotinamide phosphoribosyl transferase. AACR-NCI-EORTC International Conference Molecular Targets and Cancer Therapeutics 2007; October 22-26, 2007 San Francisco, California 2007.

15. Olesen UH, Christensen MK, Bjorkling F, Jaattela M, Jensen PB, Sehested M, Nielsen SJ: Anticancer agent CHS-828 inhibits cellular synthesis of NAD. Biochem Biophys Res Commun 2008, 367(4):799-804.

16. Wang T, Zhang X, Bheda P, Revollo JR, Imai S, Wolberger C: Structure of Nampt/PBEF/visfatin, a mammalian NAD+ biosynthetic enzyme. Nat Struct Mol Biol 2006, I 3(7):66 I-662.

17. Dhar S, Nygren P, Csoka K, Botling J, Nilsson K, Larsson R: Anticancer drug characterisation using a human cell line panel representing defined types of drug resistance. Br J Cancer 1996, 74(6):888-896.

18. Nygren P, Fridborg H, Csoka K, Sundstrom C, de la Torre M, Kristensen J, Bergh J, Hagberg H, Glimelius B, Rastad J, et al.: Detection of tumor-specific cytotoxic drug activity in vitro using the fluorometric microculture cytotoxicity assay and primary cultures of tumor cells from patients. Int J Cancer 1994, 56(5):715-720.

19. Larsson R, Kristensen J, Sandberg S, Nygren P: Laboratory determination of chemotherapeutic drug resistance in tumor cells from patients with leukemia using a fluorimetric microculture cytotoxicity assay (FMCA). Int J Cancer 1992, 50: I77-I85.

20. Larsson R, Nygren P: A rapid fluorometric method for semiautomated determination of cytotoxicity and cellular proliferation of human tumor cell lines in microculture. Anticancer Res 1989, 9: I|||-|| 20 
21. Tagmose TM, Schou SC, Mogensen JP, Nielsen FE, Arkhammar PO, Wahl P, Hansen BS, Worsaae A, Boonen HC, Antoine MH, et al:: Arylcyanoguanidines as activators of Kir6.2/SURIK ATP channels and inhibitors of insulin release. J Med Chem 2004, 47( I 2):3202-32II.

22. Nemeth ZH, Deitch EA, Lu Q, Szabo C, Hasko G: NHE blockade inhibits chemokine production and NF-kappaB activation in immunostimulated endothelial cells. Am J Physiol Cell Physiol 2002, 283(2):C396-403.

23. Ekelund S, Persson I, Larsson R, Nygren P: Interactions between the new cytotoxic drug CHS 828 and amiloride and mitomycin $C$ in a human tumour cell line and in tumour cells from patients. Chemotherapy 2002, 48(4): 196-204.

24. Chern JH, Shia KS, Chang CM, Lee CC, Lee YC, Tai CL, Lin YT, Chang CS, Tseng HY: Synthesis and in vitro cytotoxicity of 5-substituted 2-cyanoimino-4-imidazodinone and 2-cyanoimino-4pyrimidinone derivatives. Bioorg Med Chem Lett 2004, | 4(5): I |69-1 I 72.

25. Beauparlant P, Bedard D, Bernier C, Chan H, Gilbert K, Goulet D, Gratton MO, Lavoie M, Roulston A, Turcotte E, et al:: Preclinical development of the nicotinamide phosphoribosyl transferase inhibitor prodrug GMX 1777. Anticancer Drugs 2009, 20(5):346-354.

Publish with Bio Med Central and every scientist can read your work free of charge

"BioMed Central will be the most significant development for disseminating the results of biomedical research in our lifetime. "

Sir Paul Nurse, Cancer Research UK

Your research papers will be:

- available free of charge to the entire biomedical community

- peer reviewed and published immediately upon acceptance

- cited in PubMed and archived on PubMed Central

- yours - you keep the copyright

Submit your manuscript here:

http://www.biomedcentral.com/info/publishing_adv.asp
BiolMedcentral 